\title{
Effects of Tumor Microenvironment Acidification on Progression of Pancreatic Ductal Adenocarcinoma: A Review
}

\author{
Manh Tien Tran ${ }^{1}$
}

Cite this article: Tran MT: Effects of tumor microenvironment acidification on progression of pancreatic ductal adenocarcinoma: A review. Asia-Pac J Oncol 2021; 2: 27-34. https://doi. org/10.32948/ajo.2021.08.14

\begin{abstract}
Pancreatic ductal adenocarcinoma (PDAC) is an aggressive and devastating disease, which is characterized by invasiveness, rapid progression and profound resistance to treatment. It has been best characterized that tumor microenvironment such as hypoxia and nutrient deprivation contributes to cancer progression; however, the role of tumor microenvironment acidification (TMA), a major feature of tumor tissue, has not been intensively studied. Interestingly, clinicopathological clues have recently unraveled that TMA is involved in promoting cancer progression although the exact signaling pathways is poorly understood. In PDAC, the TAM is tightly regulated by proton $(\mathrm{H}+)$ transporters and pumps. This review dissects and summarizes the roles of these $\mathrm{H}+-$ extruding regulators in facilitating PDAC progression.
\end{abstract}

Key words $\mathrm{H}+$ transporters, $\mathrm{H}+$ pumps, TMA, PDAC

1. Department of Dental Pharmacology, Graduate School of Medicine, Dentistry and Pharmaceutical Sciences, Okayama University, Okayama 700-8525, Japan.

Correspondence: Manh Tien Tran (Department of Dental Pharmacology, Graduate School of Medicine, Dentistry and Pharmaceutical Sciences, Okayama University, 2-5-1 Shikata-cho, Kita-ku, Okayama, 700-8525, Japan; E-mail: trantienmanh1508@gmail.com). 


\section{Introduction}

PDAC is the most prevalent neoplastic disease of the pancreas responsible for more than $90 \%$ of all pancreatic malignancies [1], and is the third leading cause of cancer-related morbidity and mortality in both sexes, with a 5-year overall survival rate below $5 \%$ and a median survival of less than 6 months [2]. PDAC is associated with extremely poor prognosis, and the surgical resection followed by adjuvant chemotherapy drugs such as gemcitabine, erlotinib, FOLFIRINOX [3, 4] and/or a combination of nanoparticle albumin-bound-bound (nab)-paclitaxel and gemcitabine [5] is the only curative therapy currently applicable. Yet, it is still disappointing that most patients with advanced PDAC die within 12 months of diagnosis [6].

The pancreas is a complicated organ consisted of both exocrine glands (acinar and ductal cells secreting digestive enzymes into the intestinal lumen) and endocrine $(\alpha, \beta, \delta, \varepsilon)$ glands, also known as the islets of Langerhans, which are responsible for secreting hormones into the blood stream [7]. Under certain extracellular stimuli such as tissue damage, stress conditions, or inflammatory factors, acinar cells can transdifferentiate into cells expressing specific ductal markers [8-10]. During acinar-to-ductal metaplasia (ADM), acinar cells acquire 'progenitor cell-like' properties that render them more susceptible to pro-oncogenic hits, such as activating mutations in the proto-oncogene Kirsten rat sarcoma virus (KRAS), eventually transforming them into pancreatic intraepithelial neoplasias (PanINs). This transformation is generally considered as the initial step in PDAC development followed by sequential progression involving genetic hits in several tumor suppressor genes. Many studies have indicated that the gene encoding the proto-oncogenic GTPase KRAS as well as several tumor suppressor genes, consisting of tumor suppressor p53 (TP53), cyclin-dependent kinase inhibitor 2A (CDKN2A), and mothers against decapentaplegic homologue 4 (SMAD4), exhibit the most frequent alterations and/or mutations in PDAC [11, 12]. Besides, RAC-beta serine/threonine-protein kinase (AKT2) is frequently overexpressed [13, 14], and the activity of its upstream regulator phosphoinositide 3-kinase (PI3K) is often enhanced in PDAC, which leads to increased cancer cell survival $[15,16]$.

The PDAC tumor microenvironment (TME) is principally consisted of various cell types such as fibroblasts, endothelial cells, neurons, and infiltrating immune cells as well as the extracellular matrix (ECM) proteins such as cytokines, growth factors and blood vessels. The majority of the PDAC histology is desmoplasia derived from the stroma/desmoplastic reactions. The interactions amongst components in TME and the cancer cells play a central role in facilitating immune escape, tumor progression, and metastasis. The major characteristics of TME include hypoxia, nutrient deprivation and extracellular acidification that are thought to be the potential activators of cancer progression and metastasis. Whereas hypoxia and nutrient deprivation have been welldocumented, TMA in PDAC has not been intensively studied. However, recent studies have confirmed that TAM is involved in initiating the early events of malignant transformation [17-20]; more crucially, promoting tumor progression and metastasis. In the context of TMA-mediated cancer progression, it is well known that invasiveness and metastasis of cancer cells are accelerated by a variety of extracellular proteases such as metalloproteinases (MMPs), thiol proteases, serine proteases and acid proteases, which are responsible for degrading the tumor barriers, creating ideal condition to favor tumor metastasis. Notably, the proteolytic activity of these enzymes could be optimized in the TMA.

Cancer cells exert aerobic glycolysis to generate energy and supply intermediates for macromolecule biosynthetic that are required for cell survival, differentiation and proliferation [21]. A common by-product generated by this metabolic pathway is lactate, which is converted from pyruvate by lactic acid dehydrogenase-A (LDHA) [22]. The cytosolically accumulated lactate is extruded into the TME via activated $\mathrm{H}+$-linked monocarboxylate transporters (MCTs), subsequently acidifying TME [23]. Lactate activates vascular endothelial growth factor (VEGF) [24], transforming growth factor beta (TGFß) [25], interleukin-1 (IL1) [26] and HIF-1 [27]. Also, it is worth noting that glycolytic inactivation in cancer cells still facilitates acidification of the TME [28-30], indicating that the $\mathrm{H}+$ efflux pathways might be regulated by other $\mathrm{H}+$ extruders, in addition to MCTs, which include $\mathrm{Na}+$ / $\mathrm{H}+$ exchangers (NHEs) [31, 32], sodium/bicarbonate transporters (NBCs) [33], V-type H+ ATPases [34, 35], and carbonic anhydrases (CAs) [36]. Therefore, addressing the question of why cancer cells, but not normal, non-transformed cells, can thrive in the TME is of utmost importance since therapies interfering with the TME might provide useful clinical strategies for patients with cancer. This review will summarize the specific roles of $\mathrm{H}+$ transporters, pumps and channels in facilitating the PDAC development and progression.

\section{MCTs}

In the absence of oxidative phosphorylation, the glycolytic metabolism of cancer cells is initially facilitated by the uptake of glucose via glucose transporters (GLUTs), which belong to the solute carrier (SLC2A) family of transport proteins [37]. Lactate, the glycolytic end-product generated by PDAC cells, is extruded into the TME via the MCT1 [38]. MCTs are encoded by the solute carrier 16 (SLC16) family of genes. Among the 14 members of this family, MCT1/SLC16A1, MCT2/SLC16A7, MCT3/SCL16A8, and MCT4/SCL16A3 (hereafters referred to as MCTs) convey monocarboxylate ions together with $\mathrm{H}+$ ions. In most cases, the lactate taken up by cancer cells derives from surrounding stromal cells, such as fibroblasts. The lactate/H+ MCT1 and MCT4 play a pivotal role in transferring energy through establishing a lactateshuttle system. Under this condition, MCT1 favors cellular lactate-uptake, while MCT4 rather exports lactate [39]. In PDAC, Sukeda et al. previously reported that MCT4 that was expressed in cancer-associated fibroblasts (CAFs) tended to shorten overall and progression-free survival, whereas MCT1 expression was associated with prolonged survival and reduced lymph node metastasis [40], suggesting a multi-directional functionality of MCTs-mediated lactate secretion into TME upon facilitating development and progression of PDAC. However, De-Hai Wu et al. showed that miR-124-mediated MCT1 suppression abolished the glycolytic activity and altered intracellular acidification of PANC-1 cells, and more importantly, reduced the tumor phenotype in vitro and in vivo [41]. Besides, CD147, a membrane protein highly enriched on many human epithelial cancer cells, including PDAC, has recently been identified as a vital regulator of several membrane transporters, comprising MCT-1 and MCT-4 [42]. An important role of CD147 is to promote the synthesis of MMPs in CAFs [43, 44], suggesting that CD147 might be involved in altering the TME to favor invasiveness and metastasis. Indeed, knockdown of CD147 expression weakened tumorigenicity through inhibiting the lactate transport in both in vitro and in vivo models [42]. Furthermore, CD147 has also been associated with glutamine transport [45] and $\mathrm{Ca} 2+$ signaling [46], suggesting that CD147 might be a potent target for therapeutic treatments of patients with PDAC.

Alternatively, lactate discharging might be mediated through gap junctions that are connected by connexin channels. Previously Dovmark et al. demonstrated that $\mathrm{Cx} 43$ channels played a role as the crucial conduits for transmitting lactate from glycolytic PDAC cells into the neighboring cells, which triggers alkalization of recipient cells [47]. Markedly, cell-cell contact via this junctional 


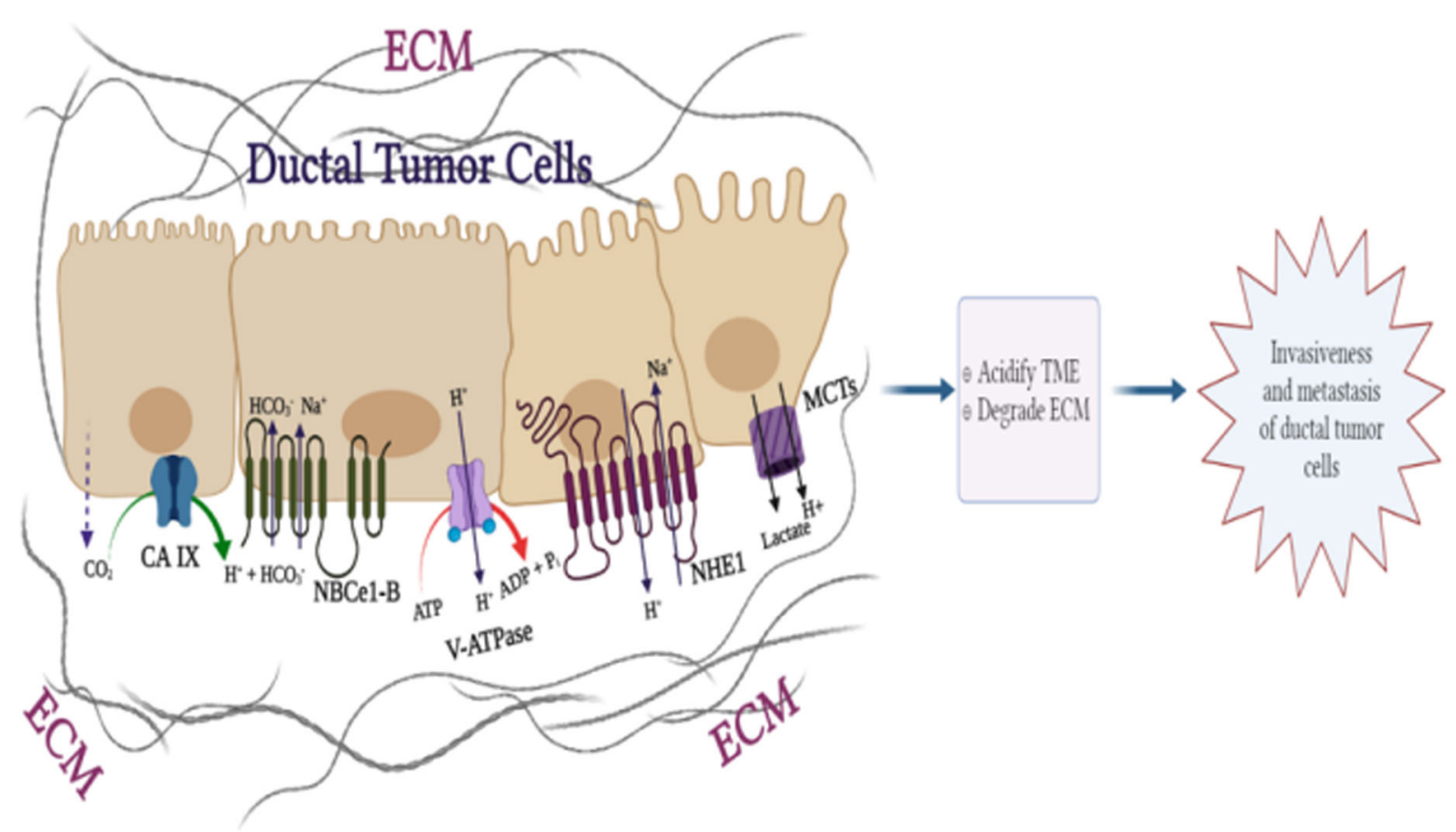

Figure 1. The possible mechanism underlying the TMA-mediated regulation of invasiveness and metastasis. The anaerobic glycolysis of ductal tumor cells enhances lactate production. Then, lactate is transported across plasma membrane via MCTs, mainly MCT-1 and -4 in a H+-dependent manner. In PDAC cells, NHE1, V-ATPases, and CA IX are frequently overexpressed to enhance the $\mathrm{H}+$ transport into extracellular milieu, contributing to acidify the TME. Acidification of the TME subsequently provides the ideal milieu for enzymatic activity of MMPs to degrade the ECM, thereby facilitating the invasiveness and metastasis of PDAC cells.

flux is thermodynamically insensitive to TME, which possibly compensates for the TME-induced reduction of MCT activity. PDAC tumors are characterized by profoundly under-perfused regions requiring efficient mechanisms for discharging and transmitting lactate across clusters of PDAC cells [47], towards specific regions that possess the most favorable transmembrane gradient for MCT-assisted off-loading lactate. Due to it, the junctional flux of lactate benefits tumor growth through (1) providing an extracellular $\mathrm{pH}(\mathrm{pHe})$-insensitive route for discharging metabolic wastes from glycolytic PDAC cells, and (2) alkalizing neighboring cells such as fibroblasts. It is suggested that blocking Cx43 channels by the specific blocker such as inoxynil and ioxynil octanoate might be a promising strategy to inhibit PDAC progression. However, more in vivo experiments using animal models are needed to test the anti-cancer efficaciousness of these specific blockers of $\mathrm{Cx} 43$ channels.

\section{NHEs}

In addition to the abovementioned MCT family isoforms, NHEs have been identified to participate in the regulation of intracellular $\mathrm{pH}(\mathrm{pHi})$ and $\mathrm{pHe}$. Ten isoforms of NHEs have been identified (NHE1-NHE10). Of these, NHE1 has been studied most broadly. NHE1 plays a housekeeping role in the regulation of cell volume, cell proliferation, differentiation [48]. Activation of NHE1 inducing elevated $\mathrm{pHi}$ was reported to be an early event of oncogenic transformation, and NHE1 was proved to be essential for the maintenance of the malignant phenotype, which promotes 
cancer progression [31, 32, 49-51]. Importantly, oncogenic activation of NHE1 drives both intracellular alkalization and extracellular acidification, which prompts us that NHE1 might be a key initiator for promoting malignant transformation of solid tumors. As identified to accumulate in the leading edge of migrating cells, NHE1 plays a central role in cell migration and invasion [52]. NHE1 activity is modulated by phosphorylation of seine/threonine residues and/or binding of regulatory proteins to specific sites of the cytoplasmic tail. In pancreatic cancer cell lines (BxPC and PANC-1), Ulrike Olszewski et al. has reported that NHE1 was stimulated through the up-regulation of neurotensin (NT)/neurotensin receptor 1 (NTR1) signaling pathway, leading to promote TMA, thereby favoring the invasiveness of pancreatic cancer cells at a very early stage of tumor development [53]. Furthermore, Hui Wang et al. has revealed that LAMC2, laminin subunit gamma 2, activated Akt signaling, which subsequently triggered NHE1 up-regulation, resulting in acceleration of TMA, thereby enhancing the invasiveness of pancreatic cancer cell lines (PANC-1 and AsPC-1) [31]. Interestingly, epidermal growth factor (EGF) promoted the interaction between NHE1 and EGFR via the scaffolding protein $\mathrm{Na}+\mathrm{H}+$ exchanger regulatory factor 1 (NHEF1), driving both basal and EGF-stimulated threedimensional growth and early invasion via invadopodial ECM digestion in PDAC cells lines (PANC-1, BXPC3, MiaPaCa-2 and CAPAN-2) [54]. Consequently, inhibiting NHE1 by its specific blockers might potently abrogate the PDAC development and progression. However, because NHE1 is best-characterized to be crucial for regulating the fluid homeostasis and secretion in the epithelial acinar and duct cells such as saliva, pancreas, small intestine, it is believed that numerous severe side-effects unwanted might occur.

Besides, other NHE isoforms, such as NHE6 and NHE9, have also been confirmed to be essential for tumor $\mathrm{pH}$ regulation, carcinogenesis, and development of chemoresistance [55, 56]. NHE7 localized in the trans-Golgi network (TGN) played a role in acidifying the TGN and controlling pHi in PDAC cells [57]. NHE7 was up-regulated in PDAC tumors, and correlated with poor prognosis and patient survival [58].

\section{NBCs and CAs}

In addition to $\mathrm{H}+$ and lactate, the excessive extrusion of $\mathrm{CO} 2$ and limited distribution of blood vessels in tumor sites contributes to extracellular $\mathrm{CO} 2$ hydration, which results in acidification of TME. NBCs play a specific role in pHi regulation through moving $\mathrm{HCO} 3$ - into cells and compensate for intracellular $\mathrm{H}+$ [59]. There are five identified NBCs including NBCe1, NBCe2, NBCn1, NDCBE, and NBCE [59]; each of these exhibits distinct biochemical and pharmacological properties. The previous studies elucidated NBC-mediated acid extrusion mechanisms in vitro and in vivo in a variety of cancer cells, and the biological functions of NBCs on promoting cancer cell growth and progression [33, 60, 61]. Notably, NBCn1 (SLC4A7) was identified to be essential for ErbB2-mediated pHi regulation in breast cancer tissue through accelerating a pathway for cellular uptake of $\mathrm{HCO}_{3}$-. Specifically, using NBCn1-KO mice, the authors indicated that disrupting NBCn1 expression abolished ErbB2-mediated development and progression of breast cancer cells, and decelerated tumor growth [62]. Moreover, other studies indicated that NBCe1 (SLC4A4) was a vital regulator of the proliferation, migration and invasion of colon cancer cells (LS174 and DLD I) [61], breast cancer cells (MDA-MB-231) [61], and prostate cancer cells (LNCaP and PC3) [33]. In addition to NBCe1, it was demonstrated that inhibition of NDCBE (SLC4A8) and/or NBCE (SLC4A10) also weakened breast cancer cell growth [63]. However, it is obscure whether NBCs are involved in the development and progression of PDAC.
More works should be addressed to investigate their role in PDAC progression in future.

Additionally, conversion of $\mathrm{CO} 2$ to $\mathrm{HCO} 3-$ and $\mathrm{H}+$ is catalyzed by CAs that are the transmembrane zinc metallo-enzymes. In mammals, there are five cytosolic forms (CA I, CA II, CA III, CA VII, and CA XIII), five membrane-bound enzymes (CA IV, CA IX, CA XII, CA XIV, and CA XV), two mitochondrial forms (CA VA and CA VB), and a secreted CA isozyme (CA VI) [64]. Among CA isoforms, CA IX is best characterized to be critical for regulating $\mathrm{pHi}$ [65] and acidifying extracellular environment [66]. CA IX is tightly associated with promotion of the aggressive/ invasive phenotype of tumors [67]; importantly, it was identified to be a prominent biomarker of poor patient prognosis for many solid cancers [68]. CA IX that was activated by the HIF-1 $\alpha$ pathways under hypoxic conditions played an important role in maintaining the hypoxic tumor microenvironment, which promoted tumor growth [68]. Structurally, CA IX consisting of an N-terminal proteoglycan-like domain, a CA domain, a transmembrane anchor that is associated with plasma membrane via a singlepass transmembrane region, and a $\mathrm{C}$-terminal cytoplasmic tail, is responsible for ameliorating the $\mathrm{CO} 2$ hydration as well as accelerating $\mathrm{CO} 2$ diffusion and $\mathrm{H}+$ mobility in the tumor tissue. Moreover, it was demonstrated that CA IX spatially and functionally cooperated with a variety of acid extruders and HCO3- transporters such as NBCe1-B, NBCn1 [69-71], and/or lactate and H+-exporting MCT1, MCT4, and NHE1 [72]. Recently, CA IX has recently been identified to be a pro-migratory factor facilitating cell movement and invasion by weakening intercellular adhesion and increasing cell dissociation via alleviating E-cadherin binding to $\beta$-catenin [70, 73]. In PDAC, McDonald et al. revealed an important role of CA IX in mediating the survival of pancreatic cancer cells by modulating $\mathrm{pHi}$ and glycolysis under hypoxic conditions [74]. Furthermore, Yuji Li et al. reported that knockdown of CA IX expression markedly inhibited the invasiveness and metastasis of PDAC cells lines (AsPC-1 and Miacapa), suggesting a pro-tumorigenic role of CA IX in initiating the PDAC progression [75]. Together, blocking the functional roles of CA IX might be an up-and-coming solution to alleviate the PDAC development and progression.

\section{V-type H+ ATPases}

In contrast to MCTs, NHEs and NBCs, V-ATPases that are ATPdriven enzymes, are abundantly present in endosomal-lysosomal system, Golgi apparatus, and other intracellular vacuoles and exclusively found in plasma membrane of specialized cell types and some cancer cells $[76,77]$. V-ATPases play a cardinal role in acidifying these intracellular vacuoles, by facilitating localized concentration of $\mathrm{H}+$ in acidic vesicles of the endocytic and exocytic pathways [78], which contributes to regulate important cellular processes including receptor endocytosis and vesicular trafficking [79]. Furthermore, V-ATPases provide the H+ motive force required for the formation of synaptic vesicles and subsequent accumulation of neurotransmitters [80]. In pancreatic cells, cellular pHi-dependent V-ATPase activation is crucial for insulin exocytosis [81]. In addition, V-ATPases govern the fissionfusion balance of vesicular system by interacting with Soluble NSF Attachment protein Receptor (SNARE) and GTPase [82]. Structurally, V-ATPase is a rotary nanomotor consisted of multiple subunits. Subunits are arranged in two domains: a peripheral V1 domain, which is responsible for ATP hydrolysis and an integral membrane domain $\mathrm{V} 0$, which is responsible for $\mathrm{H}+$ translocation [83]. V1 comprises subunits A-H, V0 subunits (a, d, e, c, c'), and accessory subunit Ac45. The structure of V-ATPase is highly conserved amongst all eukaryotic cells and is involved in diverse functions throughout species. 
In the context of cancer, plasma membrane V-ATPases are necessary to maintain not only an alkaline intracellular environment that is favorable for cancer cell growth, but also an acidic extracellular environment that favors cancer cell invasion [84]. Specifically, the elevated expression levels of plasma membrane V-ATPases were found in metastatic breast cancer cells [85], and blocking V-ATPases by specific inhibitors such as bafilomycin and concanamycin A (ConA) diminished the invasiveness of these cells in a manner proposed to involve plasma membrane-localized V-ATPases. Interestingly, the similar effects of blockade of V-ATPase activity were observed in melanoma cells [34] and prostate cancer cells [86, 87].

V-ATPase function is of particular interest in PDAC, given the reliance of this exceptionally aggressive cancer on nutrient scavenging, and increased lysosomal catabolism, processes critically dependent on V-ATPase activity. In PDAC patient tissues, expression levels of V-ATPase subunits V1E and V0c were correlated with cancer stage. Nonetheless, contrary to what was found in other cancer cells, V-ATPase inhibition did not consistently weaken the invasiveness of PDAC cells. Concanamycin-induced blockade of V-ATPase activity enhanced MMP2 activity, but weakened MMP9 activity [88]; however, in general, the inhibition of V-ATPase activity alleviated the invasiveness of PDAC cells [88]. Furthermore, V-ATPase activity is confirmed to be essential for degrading MT-MMP $[89,90]$, which was important for promoting the invasiveness of PDAC cells $[91,92]$. Hayashi et al. previously reported that vacuolar $\mathrm{V}$-ATPases was essential for regulating the transport of $\mathrm{H}+$ from cytosol into endocytic organelles and secretory vesicles, which are responsible for transporting $\mathrm{H}+$ through plasma membrane [93], indicating an important role of vacuolar V-ATPases in promoting extracellular acidification in PDAC cells. However, more studies are needed to reveal all aspects of functional roles of V-ATPases in regulating PDAC progression before establishing the drug program development that targets V-ATPases for treatment of patients with pancreatic cancer.

\section{Conclusion}

In total, I have presented the major effects of the TMA on facilitating progression of PDAC, indicating that TMA may be considered as a hallmark of PDAC. In fact, the current mechanisms underlying the TMA-mediated regulation of PDAC progression is poorly understood, and thus, more in-depth studies should be conducted to improve our knowledge of the relationship between the TMA and PDAC. This, in turn, may open a therapeutic window for pancreatic cancer treatments. In this review, the roles of $\mathrm{H}+$ transporters (NHEs, NBCs, and MCTs) and pumps (V-ATPases) in facilitating the TMA by providing the optimal conditions for MMP degradation in the ECM, may play a critical role in the invasiveness of PDAC cells (Figure 1). Therefore, blockade of such $\mathrm{H}+$ regulators by the specific blockers would be a promising approach that may provide a possible treatment for patients with pancreatic cancer.

\section{Funding}

Not applicable.

\section{Ethical policy}

No research involving experimentation on human or animal subjects was conducted.

Author contributions
The author contributed solely to the work.

\section{Competing interests}

The author declares no conflict of interest with the work.

\section{References}

1. Kleeff J, Korc M, Apte M, La Vecchia C, Johnson CD, Biankin AV, Neale RE, Tempero M, Tuveson DA, Hruban RH et al. Pancreatic cancer. Nat Rev Dis Primers 2016, 2: 16022.

2. Ilic M, Ilic I. Epidemiology of pancreatic cancer. World J Gastroenterol 2016, 22(44): 9694-9705.

3. Conroy T, Desseigne F, Ychou M, Bouché O, Guimbaud R, Bécouarn Y, Adenis A, Raoul JL, Gourgou-Bourgade S, de la Fouchardière C et al. FOLFIRINOX versus gemcitabine for metastatic pancreatic cancer. N Engl J Med 2011, 364(19): 1817-1825.

4. Burris HA, 3rd, Moore MJ, Andersen J, Green MR, Rothenberg ML, Modiano MR, Cripps MC, Portenoy RK, Storniolo AM, Tarassoff P et al. Improvements in survival and clinical benefit with gemcitabine as first-line therapy for patients with advanced pancreas cancer: a randomized trial. J Clin Oncol 1997, 15(6): 2403-2413.

5. Kunzmann V, Siveke JT, Algül H, Goekkurt E, Siegler G, Martens U, Waldschmidt D, Pelzer U, Fuchs M, Kullmann F et al. Nabpaclitaxel plus gemcitabine versus nab-paclitaxel plus gemcitabine followed by FOLFIRINOX induction chemotherapy in locally advanced pancreatic cancer (NEOLAP-AIO-PAK-0113): a multicentre, randomised, phase 2 trial. Lancet Gastroenterol Hepatol 2021, 6(2): 128-138.

6. Rahib L, Smith BD, Aizenberg R, Rosenzweig AB, Fleshman JM, Matrisian LM. Projecting cancer incidence and deaths to 2030: the unexpected burden of thyroid, liver, and pancreas cancers in the United States. Cancer Res 2014, 74(11): 2913-2921.

7. Gylfe E, Tengholm A. Neurotransmitter control of islet hormone pulsatility. Diabetes Obes Metab 2014, 16 Suppl 1: 102-110.

8. Kopp JL, von Figura G, Mayes E, Liu FF, Dubois CL, Morris JPt, Pan FC, Akiyama H, Wright CV, Jensen $\mathrm{K}$ et al. Identification of Sox9-dependent acinar-to-ductal reprogramming as the principal mechanism for initiation of pancreatic ductal adenocarcinoma. Cancer Cell 2012, 22(6): 737-750.

9. He P, Yang JW, Yang VW, Bialkowska AB. Krüppel-like Factor 5, Increased in Pancreatic Ductal Adenocarcinoma, Promotes Proliferation, Acinar-to-Ductal Metaplasia, Pancreatic Intraepithelial Neoplasia, and Tumor Growth in Mice. Gastroenterology 2018, 154(5): 1494-1508.e1413.

10. Chen NM, Singh G, Koenig A, Liou GY, Storz P, Zhang JS, Regul L, Nagarajan S, Kühnemuth B, Johnsen SA et al. NFATc1 Links EGFR Signaling to Induction of Sox9 Transcription and Acinar-Ductal Transdifferentiation in the Pancreas. Gastroenterology 2015, 148(5): 1024-1034.e1029.

11. Singhi AD, George B, Greenbowe JR, Chung J, Suh J, Maitra A, Klempner SJ, Hendifar A, Milind JM, Golan T et al. RealTime Targeted Genome Profile Analysis of Pancreatic Ductal Adenocarcinomas Identifies Genetic Alterations That Might Be Targeted With Existing Drugs or Used as Biomarkers. Gastroenterology 2019, 156(8): 2242-2253.e2244.

12. Waddell N, Pajic M, Patch AM, Chang DK, Kassahn KS, Bailey P, Johns AL, Miller D, Nones K, Quek K et al. Whole genomes redefine the mutational landscape of pancreatic cancer. Nature 2015, 518(7540): 495-501.

13. Altomare DA, Tanno S, De Rienzo A, Klein-Szanto AJ, Tanno S, Skele KL, Hoffman JP, Testa JR. Frequent activation of AKT2 kinase in human pancreatic carcinomas. J Cell Biochem 2002, 87(4): 470-476.

14. Semba S, Moriya T, Kimura W, Yamakawa M. Phosphorylated Akt/ PKB controls cell growth and apoptosis in intraductal papillary- 
mucinous tumor and invasive ductal adenocarcinoma of the pancreas. Pancreas 2003, 26(3):250-257.

15. Hobbs GA, Baker NM, Miermont AM, Thurman RD, Pierobon M, Tran TH, Anderson AO, Waters AM, Diehl JN, Papke B et al. Atypical KRAS(G12R) Mutant Is Impaired in PI3K Signaling and Macropinocytosis in Pancreatic Cancer. Cancer Discov 2020, 10(1): 104-123.

16. Chalabi-Dchar M, Cassant-Sourdy S, Duluc C, Fanjul M, Lulka H, Samain R, Roche C, Breibach F, Delisle MB, Poupot M et al. Loss of Somatostatin Receptor Subtype 2 Promotes Growth of KRASInduced Pancreatic Tumors in Mice by Activating PI3K Signaling and Overexpression of CXCL16. Gastroenterology 2015, 148(7): 1452-1465.

17. Robey IF, Baggett BK, Kirkpatrick ND, Roe DJ, Dosescu J, Sloane BF, Hashim AI, Morse DL, Raghunand N, Gatenby RA et al. Bicarbonate Increases Tumor $\mathrm{pH}$ and Inhibits Spontaneous Metastases. Cancer Research 2009, 69(6): 2260.

18. Kondo A, Yamamoto S, Nakaki R, Shimamura T, Hamakubo T, Sakai J, Kodama T, Yoshida T, Aburatani H, Osawa T. Extracellular Acidic pH Activates the Sterol Regulatory Element-Binding Protein 2 to Promote Tumor Progression. Cell Rep 2017, 18(9): 2228-2242.

19. Calorini L, Peppicelli S, Bianchini F. Extracellular acidity as favouring factor of tumor progression and metastatic dissemination. Exp Oncol 2012, 34(2): 79-84.

20. Bohn T, Rapp S, Luther N, Klein M, Bruehl TJ, Kojima N, Aranda Lopez P, Hahlbrock J, Muth S, Endo S et al. Tumor immunoevasion via acidosis-dependent induction of regulatory tumor-associated macrophages. Nat Immunol 2018, 19(12): 1319-1329.

21. Ganapathy-Kanniappan S, Geschwind J-FH. Tumor glycolysis as a target for cancer therapy: progress and prospects. Molecular cancer 2013, 12: 152-152.

22. Hirschhaeuser F, Sattler UG, Mueller-Klieser W. Lactate: a metabolic key player in cancer. Cancer Res 2011, 71(22): 6921-6925.

23. Hiremath SA, Surulescu C, Jamali S, Ames S, Deitmer JW, Becker HM. Modeling of $\mathrm{pH}$ regulation in tumor cells: Direct interaction between proton-coupled lactate transporters and cancer-associated carbonic anhydrase. Math Biosci Eng 2018, 16(1): 320-337.

24. Ruan G-X, Kazlauskas A. Lactate engages receptor tyrosine kinases Axl, Tie2, and vascular endothelial growth factor receptor 2 to activate phosphoinositide 3-kinase/Akt and promote angiogenesis. The Journal of biological chemistry 2013, 288(29): 21161-21172.

25. Tu CE, Hu Y, Zhou P, Guo X, Gu C, Zhang Y, Li A, Liu S. Lactate and TGF- $\beta$ antagonistically regulate inflammasome activation in the tumor microenvironment. J Cell Physiol 2021, 236(6): 4528-4537.

26. Wu J, Hong Y, Wu T, Wang J, Chen X, Wang Z, Cheng B, Xia J. Stromal-epithelial lactate shuttle induced by tumor-derived interleukin-1 $\beta$ promotes cell proliferation in oral squamous cell carcinoma. Int J Mol Med 2018, 41(2): 687-696.

27. De Saedeleer CJ, Copetti T, Porporato PE, Verrax J, Feron O, Sonveaux P. Lactate activates HIF-1 in oxidative but not in Warburgphenotype human tumor cells. PLoS One 2012, 7(10): e46571.

28. Helmlinger G, Sckell A, Dellian M, Forbes NS, Jain RK. Acid production in glycolysis-impaired tumors provides new insights into tumor metabolism. Clin Cancer Res 2002, 8(4): 1284-1291.

29. Yamagata M, Hasuda K, Stamato T, Tannock IF. The contribution of lactic acid to acidification of tumours: studies of variant cells lacking lactate dehydrogenase. Br J Cancer 1998, 77(11): 1726-1731.

30. Newell K, Franchi A, Pouysségur J, Tannock I. Studies with glycolysis-deficient cells suggest that production of lactic acid is not the only cause of tumor acidity. Proc Natl Acad Sci U S A 1993, 90(3): 1127-1131.

31. Wang H, Cai J, Du S, Wei W, Shen X. LAMC2 modulates the acidity of microenvironments to promote invasion and migration of pancreatic cancer cells via regulating AKT-dependent NHE1 activity. Experimental Cell Research 2020, 391(1): 111984.

32. Xie R, Wang H, Jin H, Wen G, Tuo B, Xu J. NHE1 is upregulated in gastric cancer and regulates gastric cancer cell proliferation, migration and invasion. Oncol Rep 2017, 37(3): 1451-1460.

33. Li JM, Lee S, Zafar R, Shin E, Choi I. Sodium bicarbonate transporter $\mathrm{NBCe} 1$ regulates proliferation and viability of human prostate cancer cells LNCaP and PC3. Oncol Rep 2021, 46(1).

34. Nishisho T, Hata K, Nakanishi M, Morita Y, Sun-Wada GH, Wada Y, Yasui N, Yoneda T. The a3 isoform vacuolar type H $\square$-ATPase promotes distant metastasis in the mouse B16 melanoma cells. Mol Cancer Res 2011, 9(7): 845-855.

35. McGuire C, Cotter K, Stransky L, Forgac M. Regulation of V-ATPase assembly and function of V-ATPases in tumor cell invasiveness. Biochim Biophys Acta 2016, 1857(8): 1213-1218.

36. Pastorekova S, Gillies RJ. The role of carbonic anhydrase IX in cancer development: links to hypoxia, acidosis, and beyond. Cancer Metastasis Rev 2019, 38(1-2): 65-77.

37. Ancey PB, Contat C, Meylan E. Glucose transporters in cancer - from tumor cells to the tumor microenvironment. Febs j 2018, 285(16): 2926-2943.

38. Wu DH, Liang H, Lu SN, Wang H, Su ZL, Zhang L, Ma JQ, Guo M, Tai S, Yu S. miR-124 Suppresses Pancreatic Ductal Adenocarcinoma Growth by Regulating Monocarboxylate Transporter 1-Mediated Cancer Lactate Metabolism. Cell Physiol Biochem 2018, 50(3): 924935.

39. Halestrap AP. The SLC16 gene family - structure, role and regulation in health and disease. Mol Aspects Med 2013, 34(2-3): 337-349.

40. Sukeda A, Nakamura Y, Nishida Y, Kojima M, Gotohda N, Akimoto T, Ochiai A. Expression of Monocarboxylate Transporter 1 Is Associated With Better Prognosis and Reduced Nodal Metastasis in Pancreatic Ductal Adenocarcinoma. Pancreas 2019, 48(8): 1102-1110.

41. Wu DH, Liang H, Lu SN, Wang H, Su ZL, Zhang L, Ma JQ, Guo M, Tai S, Yu S. miR-124 Suppresses Pancreatic Ductal Adenocarcinoma Growth by Regulating Monocarboxylate Transporter 1-Mediated Cancer Lactate Metabolism. Cellular Physiology and Biochemistry 2018, 50(3): 924-935.

42. Schneiderhan W, Scheler M, Holzmann KH, Marx M, Gschwend JE, Bucholz M, Gress TM, Seufferlein T, Adler G, Oswald F. CD147 silencing inhibits lactate transport and reduces malignant potential of pancreatic cancer cells in in vivo and in vitro models. Gut 2009, 58(10): 1391-1398.

43. Xu J, Lu Y, Qiu S, Chen Z-N, Fan Z. A novel role of EMMPRIN/ CD147 in transformation of quiescent fibroblasts to cancer-associated fibroblasts by breast cancer cells. Cancer letters 2013, 335(2): 380386.

44. Sun J, Hemler ME. Regulation of MMP-1 and MMP-2 Production through CD147/Extracellular Matrix Metalloproteinase Inducer Interactions. Cancer Research 2001, 61(5): 2276.

45. Ganor Y, Grinberg I, Reis A, Cooper I, Goldstein RS, Levite M. Human T-leukemia and T-lymphoma express glutamate receptor AMPA GluR3, and the neurotransmitter glutamate elevates the cancer-related matrix-metalloproteinases inducer CD147/ EMMPRIN, MMP-9 secretion and engraftment of T-leukemia in vivo. Leuk Lymphoma 2009, 50(6): 985-997.

46. Tang J, Guo YS, Yu XL, Huang W, Zheng M, Zhou YH, Nan G, Wang JC, Yang HJ, Yu JM et al. CD147 reinforces [Ca2+]i oscillations and promotes oncogenic progression in hepatocellular carcinoma. Oncotarget 2015, 6(33): 34831-34845.

47. Dovmark TH, Saccomano M, Hulikova A, Alves F, Swietach P. Connexin-43 channels are a pathway for discharging lactate from glycolytic pancreatic ductal adenocarcinoma cells. Oncogene 2017, 36(32): 4538-4550.

48. Slepkov E, Fliegel L. Structure and function of the NHE1 isoform of the $\mathrm{Na}+\mathrm{H}+$ exchanger. Biochem Cell Biol 2002, 80(5): 499-508.

49. Wang J, Zhou Y, Ma L, Cao S, Gao W, Xiong Q, Wang K, Yang L. CIAPIN1 Targeted NHE1 and ERK1/2 to Suppress NSCLC Cells' Metastasis and Predicted Good Prognosis in NSCLC Patients Receiving Pulmonectomy. Oxidative medicine and cellular longevity 
2019, 2019: 1970818-1970818.

50. Beltrán AR, Ramírez MA, Carraro-Lacroix LR, Hiraki Y, Rebouças NA, Malnic G. NHE1, NHE2, and NHE4 contribute to regulation of cell pH in T84 colon cancer cells. Pflugers Arch 2008, 455(5): 799810.

51. Wu Y, Zhang M, Liu R, Zhao C. Oxidative Stress-Activated NHE1 Is Involved in High Glucose-Induced Apoptosis in Renal Tubular Epithelial Cells. Yonsei Med J 2016, 57(5): 1252-1259.

52. Frantz C, Karydis A, Nalbant P, Hahn KM, Barber DL. Positive feedback between $\mathrm{Cdc} 42$ activity and $\mathrm{H}+$ efflux by the $\mathrm{Na}-\mathrm{H}$ exchanger NHE1 for polarity of migrating cells. J Cell Biol 2007, 179(3): 403-410.

53. Olszewski U, Hlozek M, Hamilton G. Activation of $\mathrm{Na}+/ \mathrm{H}+$ exchanger 1 by neurotensin signaling in pancreatic cancer cell lines. Biochem Biophys Res Commun 2010, 393(3): 414-419.

54. Cardone RA, Greco MR, Zeeberg K, Zaccagnino A, Saccomano M, Bellizzi A, Bruns P, Menga M, Pilarsky C, Schwab A et al. A novel NHE1-centered signaling cassette drives epidermal growth factor receptor-dependent pancreatic tumor metastasis and is a target for combination therapy. Neoplasia 2015, 17(2): 155-166.

55. Lucien F, Pelletier P-P, Lavoie RR, Lacroix J-M, Roy S, Parent J-L, Arsenault D, Harper K, Dubois CM. Hypoxia-induced mobilization of NHE6 to the plasma membrane triggers endosome hyperacidification and chemoresistance. Nature communications 2017, 8: 15884-15884.

56. Llongueras J, Kondapalli K, Hack A, Capilla-González V, Smith C, Guerrero-Cazares H, Quiñones-Hinojosa A, Rao R. Na+/H+ exchanger NHE9 affects tumor progression of human glioblastomas by altering endosomal pH (893.34). The FASEB Journal 2014, 28(S1): 893.834 .

57. Galenkamp KMO, Sosicka P, Jung M, Recouvreux MV, Zhang Y, Moldenhauer MR, Brandi G, Freeze HH, Commisso C. Golgi Acidification by NHE7 Regulates Cytosolic pH Homeostasis in Pancreatic Cancer Cells. Cancer Discov 2020, 10(6): 822-835.

58. Galenkamp KMO, Sosicka P, Jung M, Recouvreux MV, Zhang Y, Moldenhauer MR, Brandi G, Freeze HH, Commisso C. Golgi Acidification by NHE7 Regulates Cytosolic pH Homeostasis in Pancreatic Cancer Cells. Cancer discovery 2020, 10(6): 822-835.

59. Parker MD, Boron WF. The divergence, actions, roles, and relatives of sodium-coupled bicarbonate transporters. Physiol Rev 2013, 93(2): 803-959.

60. Boedtkjer E, Moreira JM, Mele M, Vahl P, Wielenga VT, Christiansen PM, Jensen VE, Pedersen SF, Aalkjaer C. Contribution of $\mathrm{Na}+, \mathrm{HCO} 3(-)$-cotransport to cellular $\mathrm{pH}$ control in human breast cancer: a role for the breast cancer susceptibility locus NBCn1 (SLC4A7). Int J Cancer 2013, 132(6): 1288-1299.

61. Parks SK, Pouyssegur J. The $\mathrm{Na}(+) / \mathrm{HCO} 3(-)$ Co-Transporter SLC4A4 Plays a Role in Growth and Migration of Colon and Breast Cancer Cells. J Cell Physiol 2015, 230(8): 1954-1963.

62. Lee S, Axelsen TV, Jessen N, Pedersen SF, Vahl P, Boedtkjer E. $\mathrm{Na}(+), \mathrm{HCO}(3)(-)$-cotransporter NBCn1 (Slc4a7) accelerates ErbB2induced breast cancer development and tumor growth in mice. Oncogene 2018, 37(41): 5569-5584.

63. Wong P, Kleemann HW, Tannock IF. Cytostatic potential of novel agents that inhibit the regulation of intracellular $\mathrm{pH}$. Br J Cancer 2002, 87(2): 238-245

64. Supuran CT. Carbonic anhydrases as drug targets--an overview. Curr Top Med Chem 2007, 7(9): 825-833.

65. Chiche J, Ilc K, Laferrière J, Trottier E, Dayan F, Mazure NM, Brahimi-Horn MC, Pouysségur J. Hypoxia-inducible carbonic anhydrase IX and XII promote tumor cell growth by counteracting acidosis through the regulation of the intracellular $\mathrm{pH}$. Cancer Res 2009, 69(1): 358-368.

66. Svastová $\mathrm{E}$, Hulíková $\mathrm{A}$, Rafajová $\mathrm{M}$, Zat'ovicová $\mathrm{M}$, Gibadulinová A, Casini A, Cecchi A, Scozzafava A, Supuran CT, Pastorek J et al. Hypoxia activates the capacity of tumor-associated carbonic anhydrase IX to acidify extracellular pH. FEBS Lett 2004, 577(3): 439-445.

67. Benej M, Pastorekova S, Pastorek J. Carbonic anhydrase IX: regulation and role in cancer. Subcell Biochem 2014, 75: 199-219.

68. Ivanov S, Liao SY, Ivanova A, Danilkovitch-Miagkova A, Tarasova N, Weirich G, Merrill MJ, Proescholdt MA, Oldfield EH, Lee J et al. Expression of hypoxia-inducible cell-surface transmembrane carbonic anhydrases in human cancer. Am J Pathol 2001, 158(3): 905-919.

69. Orlowski A, De Giusti VC, Morgan PE, Aiello EA, Alvarez BV. Binding of carbonic anhydrase IX to extracellular loop 4 of the $\mathrm{NBCe} 1 \mathrm{Na}+\mathrm{HCO} 3$ - cotransporter enhances NBCe1-mediated HCO3- influx in the rat heart. Am J Physiol Cell Physiol 2012, 303(1): C69-80.

70. Svastova E, Witarski W, Csaderova L, Kosik I, Skvarkova L, Hulikova A, Zatovicova M, Barathova M, Kopacek J, Pastorek J et al. Carbonic anhydrase IX interacts with bicarbonate transporters in lamellipodia and increases cell migration via its catalytic domain. J Biol Chem 2012, 287(5): 3392-3402.

71. Lee S, Axelsen TV, Andersen AP, Vahl P, Pedersen SF, Boedtkjer E. Disrupting $\mathrm{Na}+, \mathrm{HCO} 3-$-cotransporter $\mathrm{NBCn} 1$ (Slc4a7) delays murine breast cancer development. Oncogene 2016, 35(16): 21122122.

72. Jamali S, Klier M, Ames S, Barros LF, McKenna R, Deitmer JW, Becker HM. Hypoxia-induced carbonic anhydrase IX facilitates lactate flux in human breast cancer cells by non-catalytic function. Sci Rep 2015, 5: 13605.

73. Sedlakova O, Svastova E, Takacova M, Kopacek J, Pastorek J, Pastorekova S. Carbonic anhydrase IX, a hypoxia-induced catalytic component of the $\mathrm{pH}$ regulating machinery in tumors. Front Physiol 2014, 4: 400 .

74. McDonald PC, Chafe SC, Brown WS, Saberi S, Swayampakula M, Venkateswaran G, Nemirovsky O, Gillespie JA, Karasinska JM, Kalloger SE et al. Regulation of $\mathrm{pH}$ by Carbonic Anhydrase 9 Mediates Survival of Pancreatic Cancer Cells With Activated KRAS in Response to Hypoxia. Gastroenterology 2019, 157(3): 823-837.

75. Li Y, Dong M, Sheng W, Huang L. Roles of Carbonic Anhydrase IX in Development of Pancreatic Cancer. Pathol Oncol Res 2016, 22(2): 277-286.

76. Ramirez C, Hauser AD, Vucic EA, Bar-Sagi D. Plasma membrane V-ATPase controls oncogenic RAS-induced macropinocytosis. Nature 2019, 576(7787): 477-481.

77. Sun-Wada GH, Wada Y. Role of vacuolar-type proton ATPase in signal transduction. Biochim Biophys Acta 2015, 1847(10):1166-1172.

78. Jefferies KC, Cipriano DJ, Forgac M. Function, structure and regulation of the vacuolar $(\mathrm{H}+)$-ATPases. Arch Biochem Biophys 2008, 476(1): 33-42.

79. Futai M, Sun-Wada GH, Wada Y, Matsumoto N, Nakanishi-Matsui M: Vacuolar-type ATPase. A proton pump to lysosomal trafficking. Proc Jpn Acad Ser B Phys Biol Sci 2019, 95(6): 261-277.

80. Williamson WR, Hiesinger PR. On the role of v-ATPase V0a1dependent degradation in Alzheimer disease. Commun Integr Biol 2010, 3(6): 604-607.

81. O'Callaghan KM, Ayllon V, O'Keeffe J, Wang Y, Cox OT, Loughran G, Forgac M, O'Connor R. Heme-binding protein HRG-1 is induced by insulin-like growth factor I and associates with the vacuolar $\mathrm{H}+-$ ATPase to control endosomal $\mathrm{pH}$ and receptor trafficking. J Biol Chem 2010, 285(1): 381-391.

82. Strasser B, Iwaszkiewicz J, Michielin O, Mayer A.The V-ATPase proteolipid cylinder promotes the lipid-mixing stage of SNAREdependent fusion of yeast vacuoles. Embo j 2011, 30(20): 4126-4141.

83. Nishi T, Forgac M. The vacuolar (H+)-ATPases--nature's most versatile proton pumps. Nat Rev Mol Cell Biol 2002, 3(2): 94-103.

84. Sennoune SR, Martinez-Zaguilan R. Plasmalemmal vacuolar H+ATPases in angiogenesis, diabetes and cancer. J Bioenerg Biomembr 2007, 39(5-6): 427-433. 
85. Cotter K, Capecci J, Sennoune S, Huss M, Maier M, MartinezZaguilan R, Forgac M. Activity of plasma membrane V-ATPases is critical for the invasion of MDA-MB231 breast cancer cells. J Biol Chem 2015, 290(6): 3680-3692.

86. Smith GA, Howell GJ, Phillips C, Muench SP, Ponnambalam S, Harrison MA. Extracellular and Luminal pH Regulation by Vacuolar $\mathrm{H}+-\mathrm{ATPase}$ Isoform Expression and Targeting to the Plasma Membrane and Endosomes. J Biol Chem 2016, 291(16): 8500-8515.

87. Michel V, Licon-Munoz Y, Trujillo K, Bisoffi M, Parra KJ. Inhibitors of vacuolar ATPase proton pumps inhibit human prostate cancer cell invasion and prostate-specific antigen expression and secretion. Int J Cancer 2013, 132(2): E1-10.

88. Chung C, Mader CC, Schmitz JC, Atladottir J, Fitchev P, Cornwell ML, Koleske AJ, Crawford SE, Gorelick F. The vacuolar-ATPase modulates matrix metalloproteinase isoforms in human pancreatic cancer. Lab Invest 2011, 91(5): 732-743.

89. Määttä M, Soini Y, Liakka A, Autio-Harmainen H. Differential expression of matrix metalloproteinase (MMP)-2, MMP-9, and membrane type 1-MMP in hepatocellular and pancreatic adenocarcinoma: implications for tumor progression and clinical prognosis. Clin Cancer Res 2000, 6(7): 2726-2734.

90. Knapinska AM, Estrada CA, Fields GB. The Roles of Matrix Metalloproteinases in Pancreatic Cancer. Prog Mol Biol Transl Sci 2017, 148: 339-354.

91. Jiang W, Zhang Y, Kane KT, Collins MA, Simeone DM, di Magliano MP, Nguyen KT. CD44 regulates pancreatic cancer invasion through MT1-MMP. Mol Cancer Res 2015, 13(1): 9-15.

92. Ding J, Liu Y, Lai Y. Identifying MMP14 and COL12A1 as a potential combination of prognostic biomarkers in pancreatic ductal adenocarcinoma using integrated bioinformatics analysis. PeerJ 2020, 8: e10419.

93. Hayashi Y, Katayama K, Togawa T, Kimura T, Yamaguchi A. Effects of bafilomycin A1, a vacuolar type H+ ATPase inhibitor, on the thermosensitivity of a human pancreatic cancer cell line. Int $\mathrm{J}$ Hyperthermia 2006, 22(4): 275-285. 